\title{
Analisis gugus fungsi pada polimer polyethylene glycol (PEG) coated-nanopartikel oksida besi hitam $\left(\mathrm{Fe}_{3} \mathrm{O}_{4}\right)$ dan biomolekul
}

\author{
Alfrie Musa Rampengan* \\ Ilmu Fisika FMIPA, Universitas Negeri Manado, Tondano, 95619, Indonesia
}

INFO ARTIKEL

Diterima 22 September 2017

Disetujui 27 Oktober 2017

\section{Key word:}

nanoparticles $\left(\mathrm{Fe}_{3} \mathrm{O}_{4}\right)$

FTIR Spectroscopy

vibration

\section{Kata kunci:}

nanopartikel $\mathrm{Fe}_{3} \mathrm{O}_{4}$

spektroskopi FTIR

getaran

*email:

alfrierampengan@unima.ac.id

*Telp:

081392242929/08114382696

\begin{abstract}
A B STR A C T
A study has been conducted for functional group analysis of polyethylene Glycol (PEG) coated nanoparticles of iron oxide $\left(\mathrm{Fe}_{3} \mathrm{O}_{4}\right)$ and biomolecules using FTIRSpectroscopy. A sample functional group analysis was performed to determine the ability of modified iron oxide nanoparticles ( $\left.\mathrm{Fe}_{3} \mathrm{O}_{4}\right)$ with the addition of PEG polymers, potentially to bind biomolecules. The presence of water molecules absorption on the surface of black iron oxide nanoparticles $\left(\mathrm{Fe}_{3} \mathrm{O}_{4}\right)$ causing bonding with PEG polymer is indicated by the absorption peak at the vibration of the $-\mathrm{OH}$ (hydroxyl) group at the wave number $3441,01 \mathrm{~cm}^{-1}$. The result of modification of black iron oxide nanoparticles $\left(\mathrm{Fe}_{3} \mathrm{O}_{4}\right)$ with $P E G$, can bind biomolecules exhibited repetition of the absorption peak on the vibration of the -OH (hydroxyl) group at wave number $3433,29 \mathrm{~cm}^{-1}$ and even the appearance of a new absorption peak on vibration CO at wave number $1350,17 \mathrm{~cm}^{-1}$.
\end{abstract}

\section{A B STRAK}

Telah dilakukan penelitian untuk analisis gugus fungsi pada sampel polimer polyethylene Glicol (PEG) coated- nanopartikel oksida besi hitam $\left(\mathrm{Fe}_{3} \mathrm{O}_{4}\right)$ dan biomolekul menggunakan FTIR-Spectroscopy. Analisis gugus fungsi sampel dilakukan untuk mengetahui kemampuan nanopartikel oksida besi hitam $\left(\mathrm{Fe}_{3} \mathrm{O}_{4}\right)$ yang dimodifikasi dengan penambahan polimer PEG, sangat berpotensi untuk mengikat senyawa biomolekul. Adanya serapan molekul air pada permukaan nanopartikel oksida besi hitam $\left(\mathrm{Fe}_{3} \mathrm{O}_{4}\right)$ yang menyebabkan terjadi ikatan dengan polimer PEG ditunjukkan dengan puncak serapan pada vibrasi gugus $-\mathrm{OH}$ (hidroksil) pada bilangan gelombang $3441,01 \mathrm{~cm}^{-1}$. Hasil modifikasi nanopartikel oksida besi hitam $\left(\mathrm{Fe}_{3} \mathrm{O}_{4}\right)$ dengan PEG, dapat mengikat biomolekul ditunjukkan pengulangan puncak serapan pada vibrasi gugus -OH (hidroksil) pada bilangan gelombang 3433,29 $\mathrm{cm}^{-1}$ bahkan munculnya puncak serapan yang baru pada vibrasi gugu C-O pada bilangan gelombang 1350,17 $\mathrm{cm}^{-1}$.

\section{Pendahuluan}

Ukuran partikel, sifat permukaan merupakan keunggulan dari nanopartikel oksida besi hitam sehingga sangat mudah termodifikasi dengan material lain. Salah satu sifat uniknya adalah keaktifan atom besi Fe pada permukaan nanopartikel oksida besi hitam $\mathrm{Fe}_{3} \mathrm{O}_{4}$ terhadap elemen material lain, dimana atom $\mathrm{Fe}$ pada permukaan nanopartikel magnetik dalam medium air berinteraksi dengan gugus hidroksil (-OH) yang akan membentuk ikatan Fe-OH. Sifat reaktif atom Fe pada permukaan nanopartikel $\mathrm{Fe}_{3} \mathrm{O}_{4}$ membuka peluang untuk dilakukannya proses modifikasi oleh polyethylen-glycole (PEG) dan juga dapat dimanfaatkan untuk mengikat biomolekul [1]. PEG adalah salah satu jenis polimer yang dapat dipakai untuk membentuk dan mengontrol ukuran partikel. PEG dapat juga berfungsi sebagai templete, yang membungkus partikel sehingga tidak terbentuk agregat lebih lanjut, disebabkan PEG menempel pada permukaan partikel dan menutupi ion positif yang bersangkutan untuk bergantung dan membesar, 
sehingga pada akhirnya akan diperoleh partikel dengan bentuk bulatan yang seragam. Pemodifikasian nanopartikel oksida besi hitam dengan penambahan PEG sangat berpotensi untuk mengikat senyawa biomolekul seperti biomolekul jenis .

Penelitian ini menunjukkan adanya ikatan atomik (gugus fungsi) pada nanopartikel oksida besi hitam $\left(\mathrm{Fe}_{3} \mathrm{O}_{4}\right)$, PEG, nanopartikel oksida besi hitam $\left(\mathrm{Fe}_{3} \mathrm{O}_{4}\right)$ yang termodifikasi dengan PEG, dan juga nanopartikel oksida besi hitam $\left(\mathrm{Fe}_{3} \mathrm{O}_{4}\right)$ termodifikasi dengan PEG dan biomolekul, menggunakan FTIR Spectroscopy.

\section{Bahan dan Metode}

Proses sintesis nanopartikel oksida besi hitam $\mathrm{Fe}_{3} \mathrm{O}_{4}$ menggunakan bahan dasar senyawa hidrat $\mathrm{FeSO}_{4} .7 \mathrm{H}_{2} \mathrm{O} \quad 0.005$ mol, $\mathrm{FeCl}_{3} .6 \mathrm{H}_{2} \mathrm{O} 0.001$ mol dan $\mathrm{NH}_{4} \mathrm{OH} 10 \%$ dengan, kecepatan pengadukkan $450 \mathrm{rpm}$, konsentrasi suhu pengadukkan $60^{\circ} \mathrm{C}$, dan lama pengadukkan 90 menit, dengan menggunakan metode kopresipitasi.

Pemodifikasian nanopartikel oksida besi hitam $\mathrm{Fe}_{3} \mathrm{O}_{4}$ menggunakan polimer poliethylene glicole (PEG), dan biomolekul jenis. Karakterisasi semua sampel digunakan Spektrofotometer Inframerah Transformasi Fourier (FTIR spectroscopy) untuk dianalisis ikatan atomiknya (gugus fungsi).

Alat-alat yang digunakan dalam sintesis nanopartikel $\mathrm{Fe}_{3} \mathrm{O}_{4}$ diantaranya yaitu gelas beker, gelas ukur, timbangan digital, spatula, labu ukur, magnetic stirrer, furnace, hot plate, ultrasonic sound, magnet permanen, pipet, dan pinset.

\section{Hasil dan Pembahasan}

Setiap gugus fungsional memiliki pita serapan inframerah yang karakteristik pada bilangan gelombang tertentu. Vibrasi setiap ikatan memberikan citra berupa puncak yang khas sehingga berguna untuk identifikasi gugus fungsi senyawa.

Melalui spektra inframerah, tabel 1 menunjukkan ikatan atomik (gugus fungsi) yang pada sampel nanopartikel oksida besi hitam $\mathrm{Fe}_{3} \mathrm{O}_{4}$, polimer polyethylene glycol (PEG), sampel nanopartikel $\mathrm{Fe}_{3} \mathrm{O}_{4}$ yang termodifikasi dengan polimer PEG dan sampel nanopartikel
$\mathrm{Fe}_{3} \mathrm{O}_{4}$ yang termodifikasi dengan polimer PEG yang telah terikat dengan biomolekul.

Tabel 1. Ikatan atomik (gugus fungsi) nanopartikel oksida besi hitam $\left(\mathrm{Fe}_{3} \mathrm{O}_{4}\right)$, Polyethylene Glicol (PEG), nanopartikel oksida besi hitam $\left(\mathrm{Fe}_{3} \mathrm{O}_{4}\right)$ yang termodifikasi dengan PEG, dan juga nanopartikel oksida besi hitam

$\left(\mathrm{Fe}_{3} \mathrm{O}_{4}\right)$ termodifikasi dengan PEG dan biomolekul

\begin{tabular}{|c|c|c|c|c|}
\hline $\begin{array}{l}\text { Ikatan } \\
\text { atomik } \\
\text { (gugus } \\
\text { fungsi) }\end{array}$ & $\mathrm{Fe}_{3} \mathrm{O}_{4}$ & PEG & $\begin{array}{c}\mathrm{Fe}_{3} \mathrm{O}_{4}+ \\
\text { PEG }\end{array}$ & $\begin{array}{c}\mathrm{Fe}_{3} \mathrm{O}_{4+}+ \\
\mathrm{PEG}+ \\
\text { Biomol } \\
\text { ekul }\end{array}$ \\
\hline$-\mathrm{OH}$ & 3448,72 & 3448,72 & 3441,01 & 3433,29 \\
\hline $\begin{array}{c}\mathrm{C}-\mathrm{H} \\
\text { asimetris }\end{array}$ & - & 2877,79 & 2885,51 & 2978,09 \\
\hline $\mathrm{H}-\mathrm{C}-\mathrm{H}$ & - & 1635,64 & 1635,64 & 1620,21 \\
\hline H-C-H & - & 1465,90 & 1465,90 & 1481,33 \\
\hline C-O & - & - & - & 1350,17 \\
\hline $\mathrm{C}-\mathrm{O}$ & - & 1342,46 & 1342,46 & 1342,46 \\
\hline $\mathrm{C}-\mathrm{O}$ & - & 1280,73 & 1280,73 & 1280,73 \\
\hline C-O & - & 1242,16 & 1242,16 & 1242,16 \\
\hline C-O-C & - & 1103,28 & 1111,00 & 1111,00 \\
\hline C-C & - & 1056,99 & 1056,99 & 1056,99 \\
\hline C-C & - & 956,69 & 956,69 & 941,26 \\
\hline C-C & - & 840,96 & 840,96 & 894,97 \\
\hline Fe- & 586,36 & - & 578,64 & 563,21 \\
\hline Otetrahedral & & & & \\
\hline $\mathrm{Fe}-$ & 408,91 & - & 401,19 & 401,19 \\
\hline Ooktahedral & & & & \\
\hline $\begin{array}{c}\text { Fe- } \\
\text { Ooktahedral }\end{array}$ & - & - & 354,90 & 354,90 \\
\hline
\end{tabular}

Gambar 1 (a) merupakan hasil analisis serapan spektrum inframerah sampel nanopartikel $\mathrm{Fe}_{3} \mathrm{O}_{4}$. Pada bilangan gelombang $586,36 \mathrm{~cm}^{-1}$ dan $408,91 \mathrm{~cm}^{-1}$ menunjukkan dua serapan yang dominan dalam spektrum sampel tersebut. Kedua puncak serapan tersebut berkaitan dengan vibrasi ikatan tetrahedral Fe$\mathrm{O}$ dan oktahedral Fe-O $[2,3]$. Puncak serapan lain yaitu pada bilangan gelombang $3448,72 \mathrm{~cm}^{-1}$ yang berkaitan dengan vibrasi gugus - $\mathrm{OH}$ (hidroksil). Munculnya puncak vibrasi ini menunjukkan adanya serapan molekul air pada permukaan nanopartikel $\mathrm{Fe}_{3} \mathrm{O}_{4}$ yang memungkinkan untuk dapat berikatan dengan polimer PEG.

Sifat polimer PEG yang mudah mengikat dan mudah larut dalam air terlihat dalam puncak serapan pada bilangan gelombang $3448,72 \mathrm{~cm}^{-1}$ 
dalam gambar 1 (b), yang berkaitan dengan vibrasi gugus $-\mathrm{OH}$ juga. Hal ini sangat jelas bahwa nanopartikel $\mathrm{Fe}_{3} \mathrm{O}_{4}$ dapat dimodifikasi dengan menggunakan polimer PEG, dan hasil analisis serapannya ditunjukkan pada gambar 1 (c), dimana terdapat perulangan puncak-puncak serapan pada vibrasi gugus - $\mathrm{OH}, \mathrm{H}-\mathrm{C}-\mathrm{H}, \mathrm{C}-\mathrm{O}$, C-O-C, dan ikatan C-C, misalnya puncak serapan pada bilangan gelombang $3441,01 \mathrm{~cm}^{-1}$ (vibrasi gugus -OH), 578,64 $\mathrm{cm}^{-1}$ dan $401,19 \mathrm{~cm}^{-}$ ${ }^{1}$ (vibrasi gugus Fe-O).

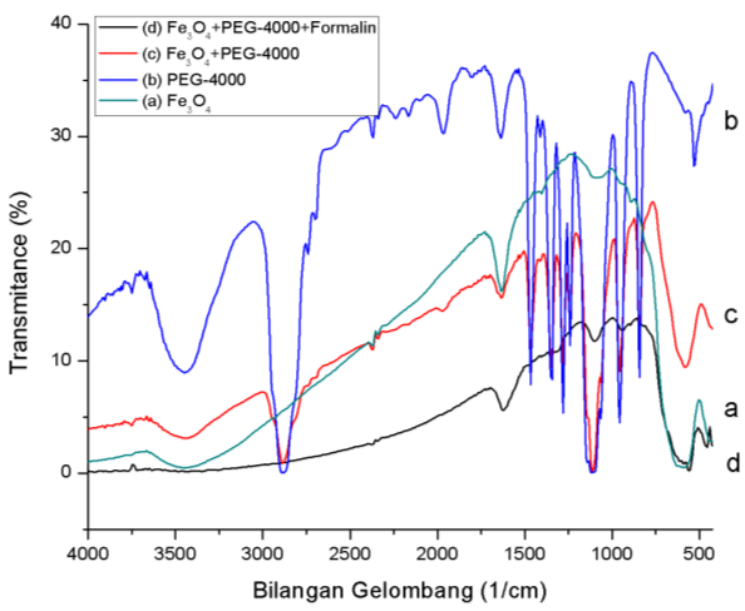

Gambar 1. Spektrum FTIR (a) sampel nanopartikel oksida besi $\left(\mathrm{Fe}_{3} \mathrm{O}_{4}\right)$ fasa kering, (b) sampel polimer polyethylene glicol (PEG), (c) sampel nanopartikel oksida besi $\left(\mathrm{Fe}_{3} \mathrm{O}_{4}\right)$ termodifikasi oleh polimer PEG, dan (d) sampel nanopartikel oksida besi $\left(\mathrm{Fe}_{3} \mathrm{O}_{4}\right)$ termodifikasi oleh polimer PEG dan biomolekul

Pergeseran puncak vibrasi ini disebabkan oleh perubahan energi vibrasi $\mathrm{Fe}-\mathrm{O}$ yang memungkinkan terjadi serapan PEG oleh atom Fe. Pada gambar 1 (d), merupakan hasil analisis serapan spektrum inframerah sampel nanopartikel $\mathrm{Fe}_{3} \mathrm{O}_{4}$ termodifikasi dengan polimer PEG yang telah terikat dengan biomolekul jenis formalin. Terdapat puncak serapan baru pada bilangan gelombang 1350,17 $\mathrm{cm}^{-1}$ (vibrasi gugus $\mathrm{C}-\mathrm{O}$ ) yang menunjukkan terbentukknya ikatan baru antara polimer PEG dan biomolekul.

Gambar 2 menunjukkan mekanisme pengikatan yang terjadi antara nanopartikel yang telah termodifikasi dengan polimer PEG yang juga telah mengikat biomolekul, dimana nanopartikel oksida besi hitam $\mathrm{Fe}_{3} \mathrm{O}_{4}$ yang telah terhubung dengan PEG melalui ikatan kovalen tunggal Fe-O, sedangkan PEG terhubung dengan biomolekul melalui ikatan kovalen tunggal O-C.

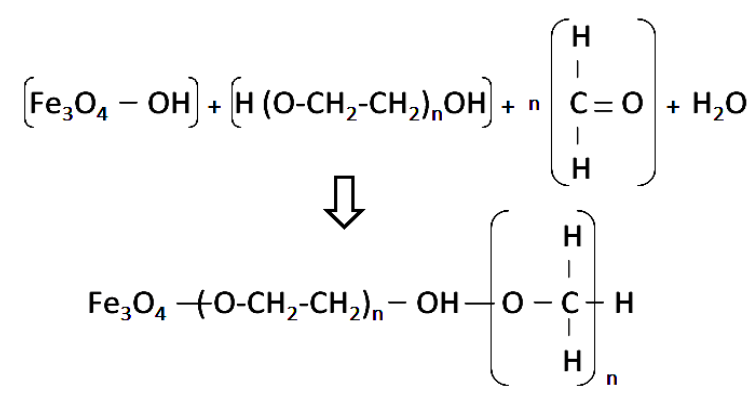

Gambar 2. Mekanisme fungsionalisasi nanopartikel $\mathrm{Fe}_{3} \mathrm{O}_{4}$ dengan PEG dan pengikatan biomolekul oleh PEG

\section{Kesimpulan}

1. Analisis gugus fungsi pada polimer PEGcoated nanopartikel oksida besi hitam $\left(\mathrm{Fe}_{3} \mathrm{O}_{4}\right)$ menunjukkan bahwa terdapat puncak serapan pada vibrasi gugus - $\mathrm{OH}$ (hidroksil), $\mathrm{H}-\mathrm{C}-\mathrm{H}, \mathrm{C}-\mathrm{O}, \mathrm{C}-\mathrm{O}-\mathrm{C}$, dan C-C.

2. Analisis gugus fungsi pada polimer PEGcoated nanopartikel oksida besi hitam $\left(\mathrm{Fe}_{3} \mathrm{O}_{4}\right)$ yang terikat dengan biomolekul menunjukkan terdapat gugus fungsi yang baru yaitu $\mathrm{C}-\mathrm{O}$ pada bilangan gelombang $1350,17 \mathrm{~cm}^{-1}$.

\section{Daftar Pustaka}

1. Loh, K.-S.; Lee, Y. H.; Musa, A.; Salmah, A. A.; Zamri, I., Use of Fe3O4 nanoparticles for enhancement of biosensor response to the herbicide 2, 4-dichlorophenoxyacetic acid. Sensors 2008, 8, (9), 5775-5791.

2. Dung, T. T.; Danh, T. M.; Duc, N. H.; Chien, D. M. In Preparation and characterization of magnetic nanoparticles coated with polyethylene glycol, Journal of Physics: Conference Series, 2009; IOP Publishing: $p$ 012048 .

3. Zhang, F.; Su, Z.; Wen, F.; Li, F., Synthesis and characterization of polystyrene-grafted magnetite nanoparticles. Colloid and Polymer Science 2008, 286, (6-7), 837-841. 